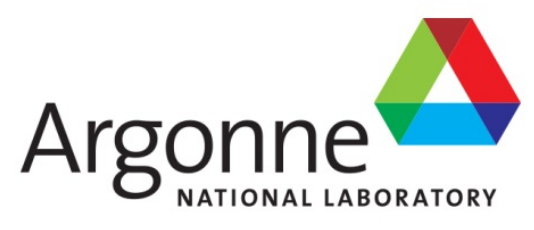

ANL/CSE-14/2

\title{
Mini-SHINE/MIPS Experiment
}

Chemical Science and Engineering Division 


\begin{abstract}
About Argonne National Laboratory
Argonne is a U.S. Department of Energy laboratory managed by UChicago Argonne, LLC under contract DE-AC02-06CH11357. The Laboratory's main facility is outside Chicago, at 9700 South Cass Avenue, Argonne, Illinois 60439. For information about Argonne and its pioneering science and technology programs, see www.anl.gov.
\end{abstract}

\title{
DOCUMENT AVAILABILITY
}

Online Access: U.S. Department of Energy (DOE) reports produced after 1991 and a growing number of pre-1991 documents are available free via DOE's SciTech Connect (http://www.osti.gov/scitech/)

Reports not in digital format may be purchased by the public from the National Technical Information Service (NTIS):

U.S. Department of Commerce

National Technical Information Service

5301 Shawnee Rd

Alexandra, VA 22312

www.ntis.gov

Phone: (800) 553-NTIS (6847) or (703) 605-6000

Fax: (703) 605-6900

Email: orders@ntis.gov

Reports not in digital format are available to DOE and DOE contractors from the Office of Scientific and Technical Information (OSTI):

U.S. Department of Energy

Office of Scientific and Technical Information

P.O. Box 62

Oak Ridge, TN 37831-0062

www.osti.gov

Phone: (865) 576-8401

Fax: (865) 576-5728

Email: reports@osti.gov

\footnotetext{
Disclaimer

This report was prepared as an account of work sponsored by an agency of the United States Government. Neither the United States Government nor any agency thereof, nor UChicago Argonne, LLC, nor any of their employees or officers, makes any warranty, express or implied, or assumes any legal liability or responsibility for the accuracy, completeness, or usefulness of any information, apparatus, product, or process disclosed, or represents that its use would not infringe privately owned rights. Reference herein to any specific commercial product, process, or service by trade name, trademark, manufacturer, or otherwise, does not necessarily constitute or imply its endorsement, recommendation, or favoring by the United States Government or any agency thereof. The views and opinions of document authors expressed herein do not necessarily state or reflect those of the United States Government or any agency thereof, Argonne National Laboratory, or UChicago Argonne, LLC.
} 


\section{Mini-SHINE/MIPS Experiment}

by

Sergey Chemerisov and George F. Vandegrift

Chemical Science and Engineering Division, Argonne National Laboratory

prepared for

U.S. Department of Energy, National Nuclear Security Administration, Office of Defense Nuclear Nonproliferation

September 14, 2011 



\section{CONTENTS}

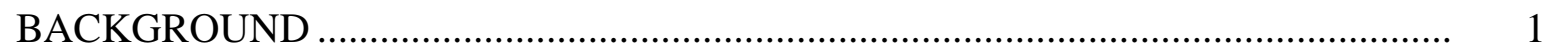

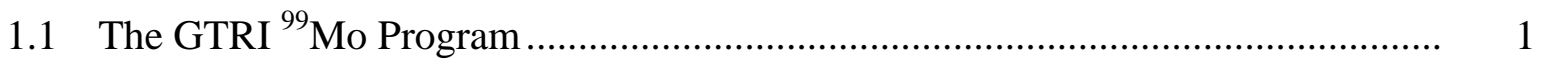

1.2 MIPS Development....................................................................................... 2

1.3 SHINE Development .............................................................................. 3

2 DESCRIPTION OF THE MINI-SHINE/MIPS EXPERIMENTS .............................. 4

3 SCHEDULE FOR THE MINI-SHINE/MIPS EXPERIMENTS................................. 11

\section{FIGURES}

1 Schematic of the Mini-SHINE/MIPS Experiment................................................. 5

2 Detailed Schematic of the Target...................................................................... 6

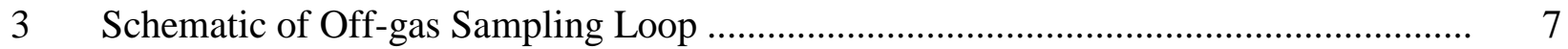

4 RGA and GC/MS to Be Used in Mini-SHINE/MIPS Gas-sampling Loop.................. 8

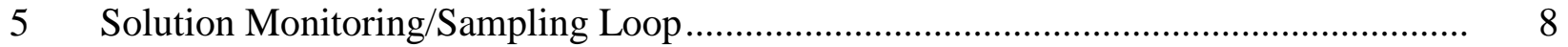

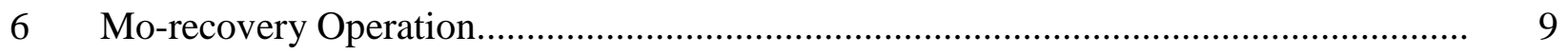

$7 \quad$ Cold-feed Table and Off-gas Collection System ................................................. 10

\section{TABLES}

$1 \quad$ Draft Schedule for Mini-SHINE Experiments................................................... 12

2 Draft Schedule for Mini-MIPS Experiments ....................................................... 13 


\section{MINI-SHINE/MIPS EXPERIMENT}

\section{BACKGROUND}

\subsection{THE GTRI ${ }^{99}$ Mo PROGRAM}

The mission of the Global Threat Reduction Initiative (GTRI) is to reduce and protect vulnerable nuclear and radiological materials located at civilian sites worldwide. The Highly Enriched Uranium (HEU) Reactor Conversion subprogram supports the conversion of domestic and international civilian research reactors and isotope production facilities from the use of weapons-of-mass-destruction- (WMD-) usable HEU fuel and targets to low enriched uranium (LEU) fuel and targets. These efforts result in permanent threat reduction because WMD-usable HEU in the civilian fuel cycle is minimized or eliminated. The main technology components of the program are (1) the development of advanced LEU fuels, (2) design and safety analysis for research reactor conversion, and (3) development of targets and processes for the production of the medical isotope molybdenum-99 ( $\left.{ }^{99} \mathrm{Mo}\right)$ without using HEU. In the scope of the last technology component of the program:

- GTRI makes technical expertise available, on a non-proprietary basis, to global medical isotope producers to assist with converting their ${ }^{99} \mathrm{Mo}$ processes to use LEU.

- GTRI provides technical support in a number of areas, including foil rolling, target fabrication, target irradiation, target disassembly, target dissolution, product recovery and purification, and waste treatment.

- These alternative LEU-based processes can replace current technologies, increase ${ }^{99}$ Mo extraction efficiency, and reduce waste volumes generated.

Currently, approximately $85 \%$ of all ${ }^{99}$ Mo is produced using HEU, ${ }^{1}$ but Argonne National Laboratory (Argonne) is making progress in lowering that fraction, both by developing technology to allow the conversion of current HEU processes and by assisting new producers to process using LEU targets. Production of the fission-product ${ }^{99}$ Mo can be characterized in five steps: (1) target fabrication; (2) target irradiation; (3) dissolution or digestion of the uranium fuel and, in some cases, the entire target; (4) recovery and purification of molybdenum from all other target components; and (5) shipment of purified ${ }^{99}$ Mo solutions to generator producers. Recovery of ${ }^{99}$ Mo varies from process to process, as does the subsequent purification operation. However, the equipment is generally small scale, with solution volumes from 0.1 to 6 liters. The use of chromatographic columns for the recovery of Mo is widespread in these processes, which have between two and six recovery/purification unit operations. The final product is sodium

1 Technetium-99m is the most commonly used medical isotope in the world, used for an estimated 25 million procedures annually. ${ }^{99 \mathrm{~m}} \mathrm{Tc}$ is a daughter of ${ }^{99} \mathrm{Mo}$, which is currently produced mainly by fissioning ${ }^{235} \mathrm{U}$ from HEU. 
molybdate in a solution of $0.2 \mathrm{M} \mathrm{NaOH}$, which is the required feed for loading the Mo into a commercial ${ }^{99 \mathrm{~m}}$ Tc generator. Total processing times vary between 4 and 14 hours. Converting to LEU from HEU will necessitate changes in the first four production steps. The GTRI goal has been to find the means to make this conversion possible, both technically and economically.

Under the GTRI program, Argonne is working with current producers around the world to convert to LEU, assisting several entities internationally in producing ${ }^{99}$ Mo for their domestic needs using LEU targets, and assisting three potential domestic entities in developing and implementing ${ }^{99}$ Mo production in the United States by 2014. Two of the potential domestic producers Argonne is assisting are Babcock and Wilcox Technical Services Group (B\&W) and Phoenix Nuclear Labs (PNL). The mini-SHINE/Medical Isotope Production System (MIPS) experiments will provide important design data for both systems. Attached are the two draft work packages for these programs.

\subsection{MIPS DEVELOPMENT}

B\&W is developing the MIPS. In this system, ${ }^{99}$ Mo is produced in an LEU-fueled aqueous homogenous reactor (AHR) by the fissioning of ${ }^{235} \mathrm{U}$. The major components of the MIPS are an AHR containing uranyl-nitrate fuel (LEU), a molybdenum-extraction system using a chromatographic column, and the reactor off-gas system. The use of AHRs presents an attractive alternative to the conventional target-irradiation method for producing ${ }^{99} \mathrm{Mo}$, in that solutions eliminate the need for targets and can operate at much lower power than required for a reactor irradiating targets to produce the same amount of ${ }^{99}$ Mo. The three subjects of Argonne research and development $(\mathrm{R} \& \mathrm{D})$ are (1) radiolytic gas generation in the fuel solution, (2) effects of fissioning and radiation on reactor-solution chemistry, and (3) recovery of molybdenum from the irradiated fuel solution.

The first solution reactors earned the name "water-boilers" because of the observed bubbling or foaming that results from the radiolytic decomposition of water by fission fragments and subsequent evolution of radiolytic gases (hydrogen and oxygen). Because nitrate ions also undergo radiolytic decomposition, uranyl-nitrate-based AHRs will also generate nitrogen compounds from $\mathrm{NO}_{2}$ to ammonia $\left(\mathrm{N}^{4+}\right.$ to $\left.{ }^{3-}\right)$, and $\mathrm{N}_{2}, \mathrm{NO}_{\mathrm{x}}$, and $\mathrm{NH}_{3}$ may be observed in the off gas. The radiolytic decomposition of nitrate ions will also increase the $\mathrm{pH}$ of the fuel solution. The rate and composition of the radiolytic gas generation is of practical importance for the design and operation of AHR for two reasons. First, the design of the reactor off-gas system depends on the generation rate and the composition of the gas stream. Second, an increase of the fuel-solution $\mathrm{pH}$ can lead to the formation of the precipitates and, therefore, must be controlled.

While radiation chemistry of nitrate solutions has been investigated over the past 50 years, less attention was given to the analysis of gas evolution, especially at high radiation doses. Observations of the formation of nitrogen-containing gases under radiation are numerous, but $\mathrm{N}_{2}$, $\mathrm{NO}_{\mathrm{x}}$, and $\mathrm{NH}_{3}$ formation was not studied systematically; no mechanism for formation of those gases was proposed. In addition, the reported values of the radiolytic yields for these gases vary by an order of magnitude. The aim of off-gas measurement system in the mini-SHINE/MIPS 
experiments is to obtain reliable data for radiolytic gas generation in uranyl-nitrate solutions that are of practical interest to the MIPS.

\subsection{SHINE DEVELOPMENT}

PNL is currently developing the Subcritical Hybrid Intense Neutron Emitter (SHINE), which creates ${ }^{99}$ Mo by neutron-induced fission of LEU in a subcritical aqueous solution. SHINE can produce a primary neutron flux on the order of $10^{12} \mathrm{n} / \mathrm{s} / \mathrm{cm}^{2}$ by the collision of multiple beams of deuterium (D) ions with tritium (T) gas targets and a secondary flux exceeding $10^{13} \mathrm{n} / \mathrm{s} / \mathrm{cm}^{2}$ with subcritical multiplication in the aqueous solution. The D-T neutron source causes the uranium to fission, further increasing the flux by one or more orders of magnitude and creating ${ }^{99}$ Mo that can be extracted from the aqueous solution and purified. In essence, SHINE is an accelerator-driven subcritical MIPS; one difference is that SHINE developers are currently considering either aqueous uranyl sulfate or nitrate as the target solution. Argonne tasks for SHINE development parallel those for MIPS development; we are developing an understanding of the solution chemistry under operating conditions and developing the Mo--recovery and purification system. Argonne is also assisting SHINE developers in facility design and developing means for periodic cleanup of the recycled target solution. 


\section{DESCRIPTION OF THE MINI-SHINE/MIPS EXPERIMENTS}

The mini-SHINE/MIPS experiments will be performed using the Argonne linac in Building 211. The experiments will use an electron/X-ray/neutron convertor to produce neutrons that will produce fissioning in solution. The solution will be either a $150 \mathrm{~g}-\mathrm{U} / \mathrm{L}$ LEU uranylnitrate (MIPS) or 90-150 g-U/L uranyl-nitrate or uranyl-sulfate solution (SHINE). In Phase 1, the convertor will be tantalum, and the target solution will have a volume of $5 \mathrm{~L}$; this will generate a fission power density of up to $0.05 \mathrm{~W} / \mathrm{mL}(1 / 20$ th of that foreseen for the MIPS and 1/10th of that foreseen for SHINE. In Phase 2, the convertor will be depleted uranium and the solution will be 10 to $20 \mathrm{~L}$; this will generate a fission power density of up to $0.5 \mathrm{~W} / \mathrm{mL}$ (1/2 of that foreseen for the MIPS and equal of that foreseen for SHINE). The volumes of the actual MIPS and SHINE units will be much larger however-200 to $500 \mathrm{~L}$.

These experiments have four major objectives:

1. Quantify the production rate and composition of radiolytic gases generated during operation of the system under varying conditions of power density, solution temperature, and startup conditions.

2. Provide information on changes of solution composition (peroxide concentration, iodine and nitrogen speciation, $\mathrm{pH}$, conductivity, solids formation), as compared to time, temperature, and fission power.

3. Demonstrate Mo recovery from the irradiated solution hours after end of irradiation.

4. Produce $2 \mathrm{Ci}$ of ${ }^{99}$ Mofor shipment to Covidien for testing in ${ }^{99 \mathrm{~m}}$ Tc generators.

To perform these experiments, the experimental setup illustrated in Figure 1 will be used. The experiment is divided into three sections - the shielded box, glovebox area, and bench top. The shielded cell will contain the convertor/solution-target, the recombiner and condensers, and the Mo-recovery column.

The electron beam enters the left side of the shielded box and strikes the convertor. The neutrons and X-rays from the convertor cause fission in the aqueous solution. Figure 2 is a more detailed illustration of the target assembly and shows the cooling/reflector region surrounding the target solution, temperature probes and neutron detector in the solution, and the catalytic convertor $\left(\mathrm{H}_{2} / \mathrm{O}_{2}\right.$ recombiner $)$ at the top of the target-solution tank and at the bottom of the gas sampling/recycle loop. The only valve in the shielded cell is a manual valve to dump the solution into a container in a shielded well.

The solution is expected to generate approximately $75 \mathrm{~mL} / \mathrm{min}$ of radiolytic gases at 0.2-kW fission power. A condenser will be situated before and after the recombiner to remove the bulk of the water vapor from the gas stream. A diaphragm pump or Roots blower will be 


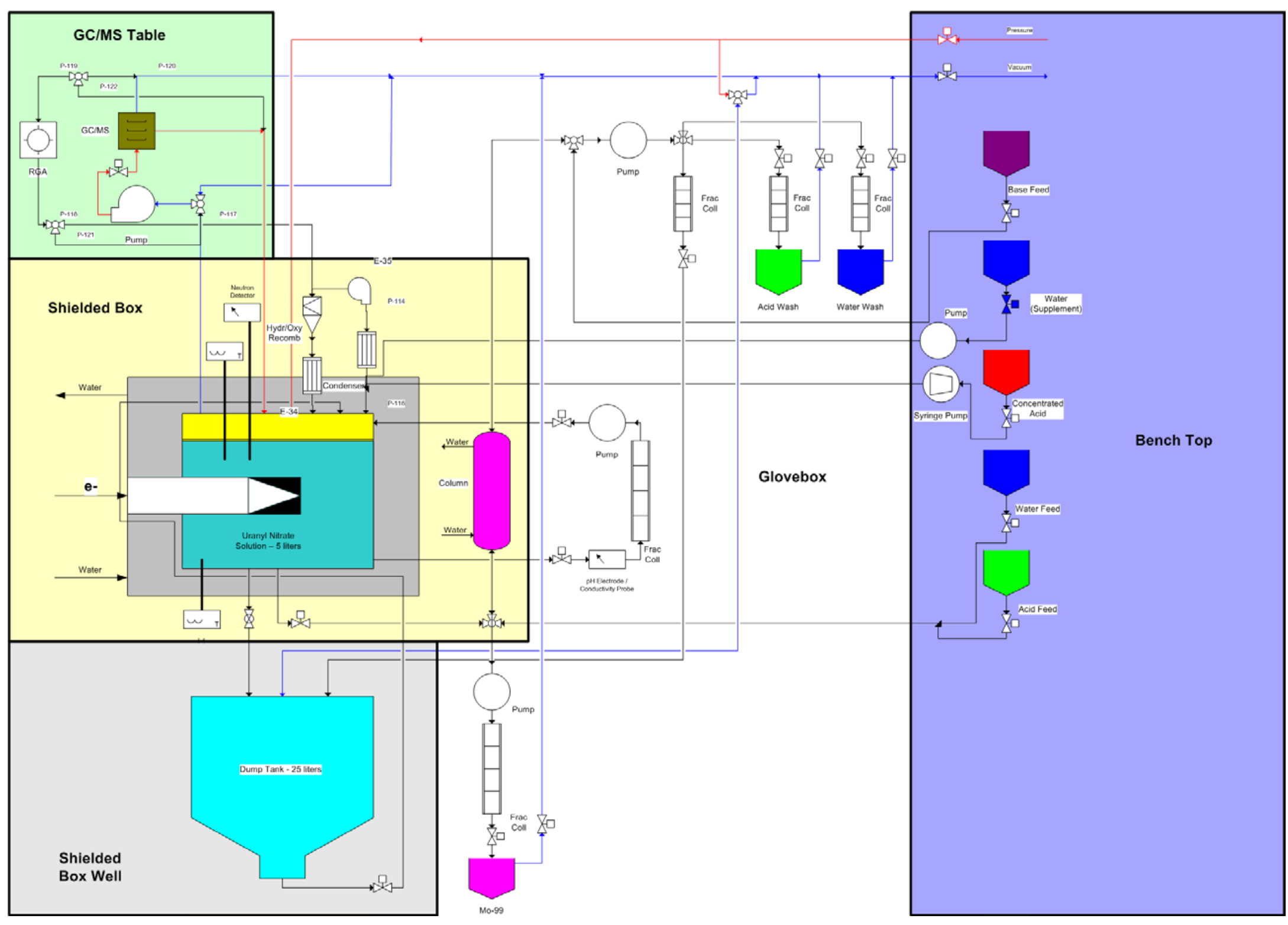

FIGURE 1 Schematic of the Mini-SHINE/MIPS Experiment 


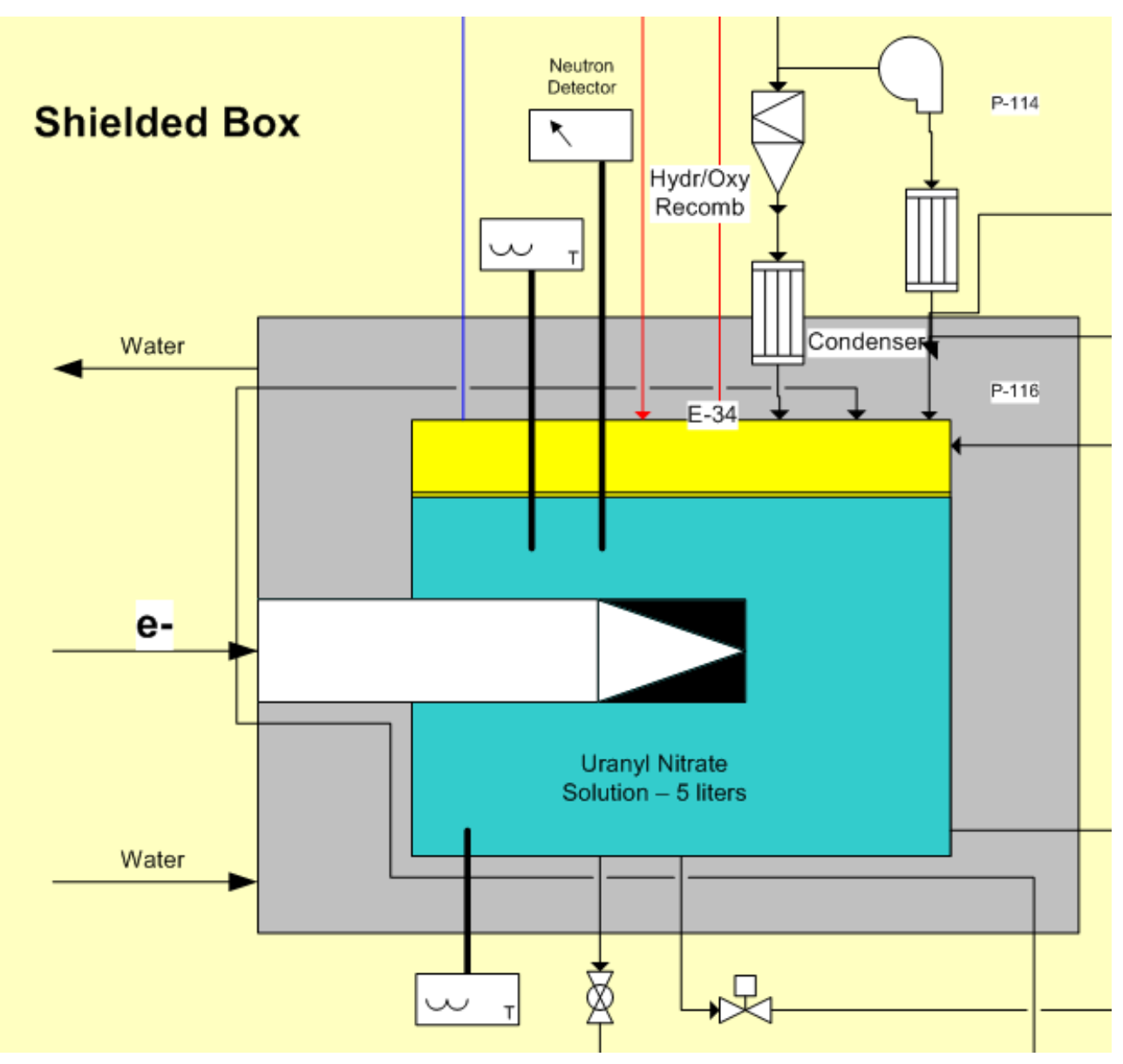

FIGURE 2 Detailed Schematic of the Target

used to create a high flow rate through the system. The recombiner is a palladium/platinum (Pt/Pd) on alumina honeycomb catalyst supplied by the Ford Motor Company. The open design of the catalyst will also allow it to handle the expected flow rates (1-12 $\mathrm{mL} / \mathrm{min})$. The CSE catalyst group has tested the catalyst at a small scale, and full-scale testing is underway. Modeling of the main irradiation volume and plenum is also underway to determine the required flow rate to dilute the hydrogen gas sufficiently. This model is also capable of determining the amount of dead volume in the plenum that may accumulate an explosive amount of radiolytic gases. The off-gas will be recycled in a closed-loop gas system during the experiment and will be discussed below. The recombiner and the condensers will be inside the shielded box; however, because of its size, the pump/blower will be in a containment box above the shielded box.

The closed-loop gas sampling system is described in Figures 3 and 4. Samples will be collected from both the headspace above the target solution and above the catalytic convertor. Both a GC/MS (gas chromatographic with a mass spectrometry detector) and an RGA (residual gas analyzer) will be used to measure the composition and generation rate of radiolytic gases. 


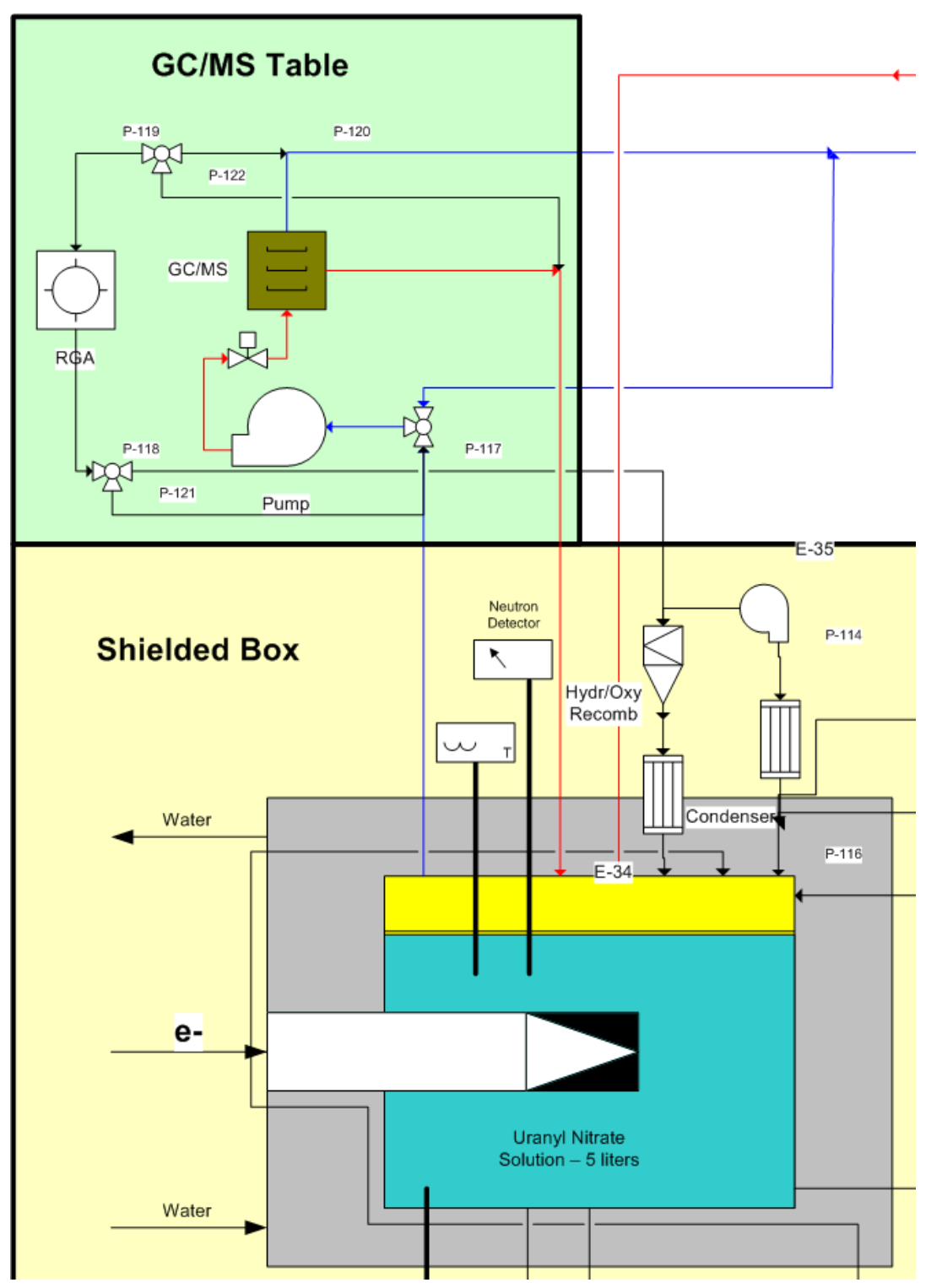

FIGURE 3 Schematic of Off-gas Sampling Loop

During irradiation, a small volume of the solution will also be pumped through a closedloop system, which will be set up in a glovebox next to the shielded cell (Figure 5). In the closed system, $\mathrm{pH}$, conductivity, and turbidity will also be monitored continually. ${ }^{2}$ The radiation stability of these components is now being tested at the Van de Graaff generator. A sampling system using syringes and step motors will collect timed samples during the run. The line and samples will be shielded. We will have the ability to add acid and water to the target solution during operation if increases in $\mathrm{pH}$ or conductivity are observed (bottom right of Figure 1). The

2 The turbidity probe is not shown in the diagram because it was recently added to our plans based on a suggestion by an NNSA review committee August 2011. 

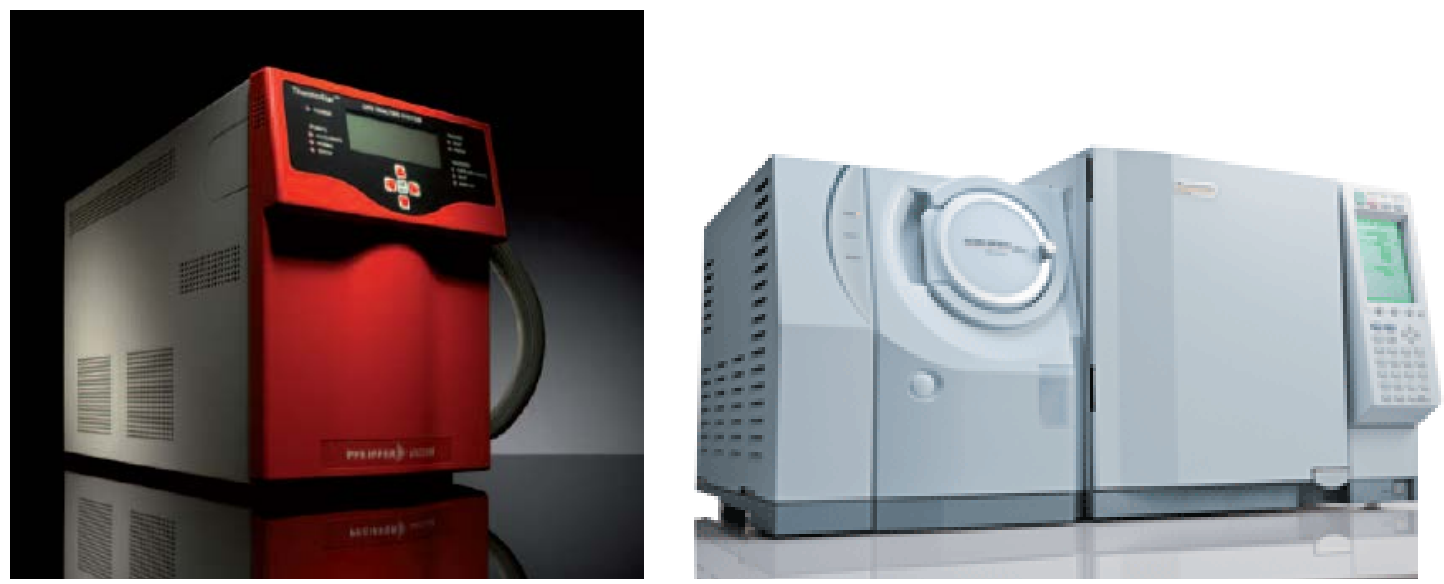

FIGURE 4 RGA and GC/MS to Be Used in Mini-SHINE/MIPS Gas-sampling Loop

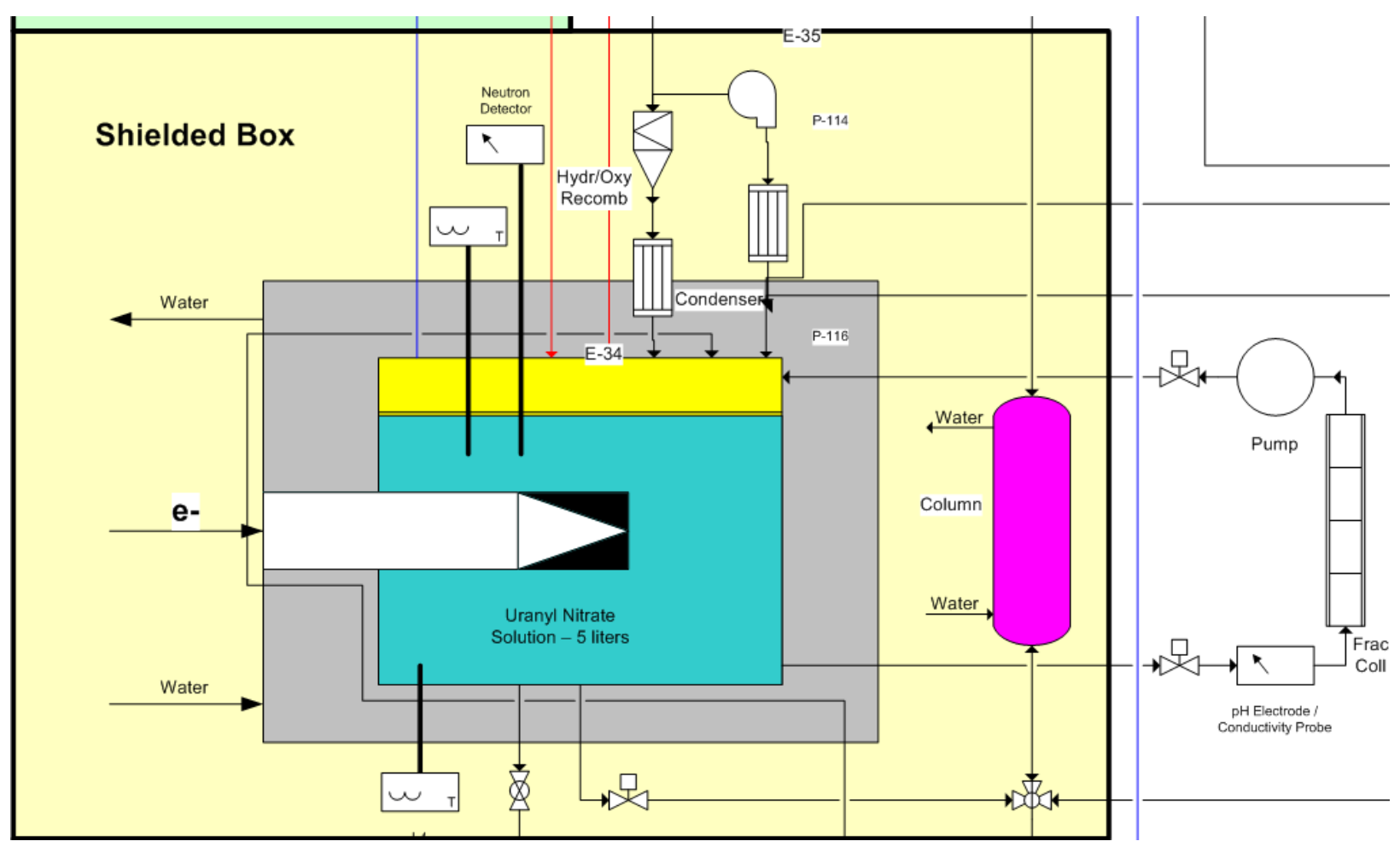

FIGURE 5 Solution Monitoring/Sampling Loop

ability to control $\mathrm{pH}$ during operation of the MIPS is one of the parameters B\&W wants to explore in these experiments.

The Mo-recovery column is also located in the shielded cell. A second glovebox will house the sampling stations (fraction collectors), and cold feeds will be added from a bench-top station (Figure 6). A few hours after the end of irradiation, the target solution will be passed 


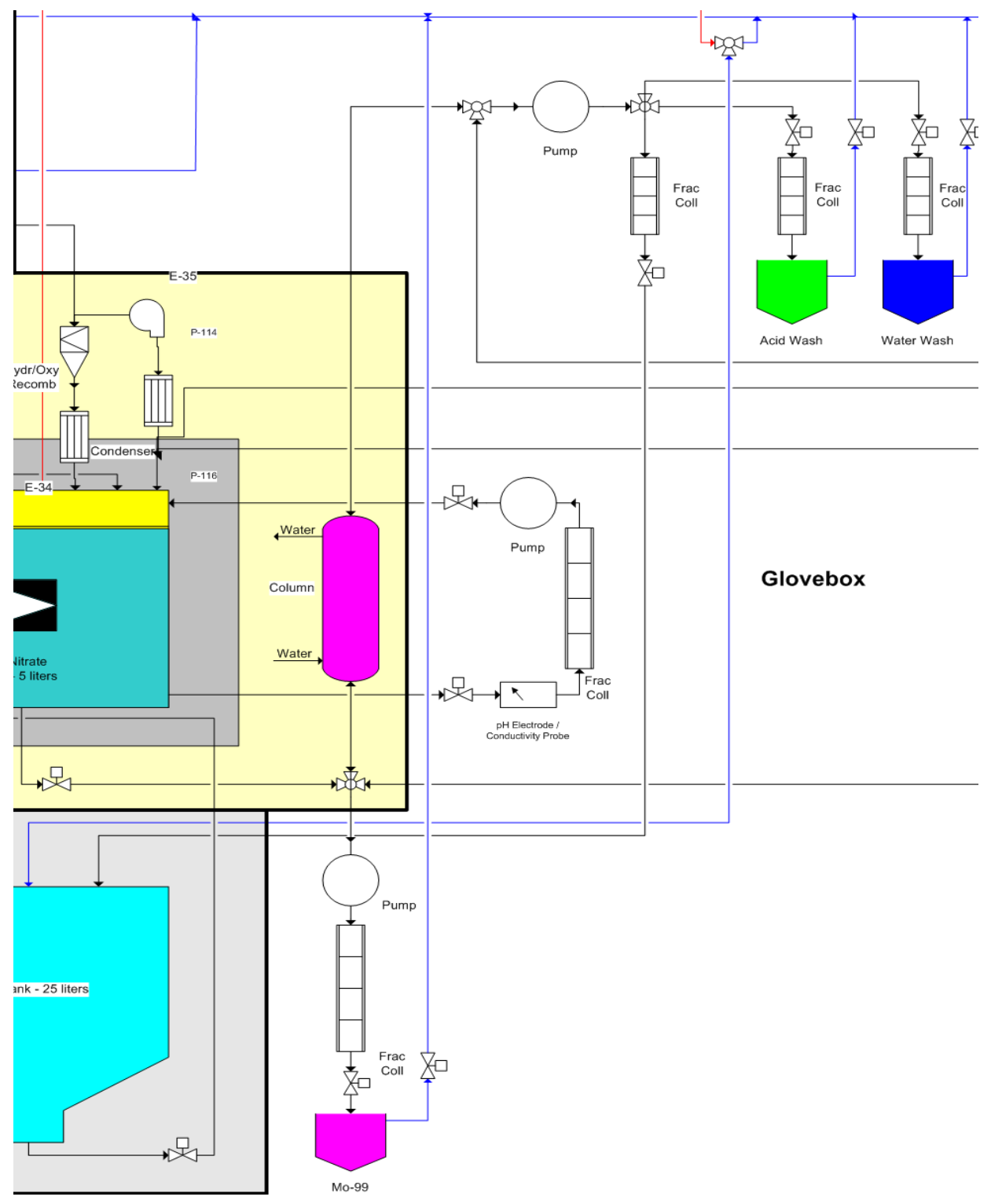

FIGURE 6 Mo-recovery Operation

through the titania column to recover Mo from the irradiated solution. A fraction of radioiodine and minor amounts of other fission and activation products will also be captured. Small samples of the effluent will be collected, and the bulk of the solution will pass into the shielded volume below the shielded box. The column will then be washed first with dilute nitric or sulfuric acid and then with a water wash. Small fractions of these effluents will also be collected. The spent wash solutions will be returned to the glovebox. All these solutions will be passed through the column in the up-flow direction. The strip solution will be $1 \mathrm{M}$ of ammonium hydroxide; it will also be run in the down-flow direction, sampled periodically, and kept in the glovebox. All sampling stations and collection vessels will be shielded. Mockups are being prepared and tested for all operations. 
At the end of the recovery operation, the Mo product will be removed from the glovebox in the linac target room and moved to a glovebox in the laser room next to it. In this glovebox, the ammonia and water will be evaporated using a rotovap (which is a closed system). Nitric acid will be added to the dry residue and also evaporated to dryness. A NaOH scrubber will be between the rotovap and the vacuum pump to trap any iodine vapors that might escape the condenser flask. This process will remove almost all the radioiodine from the solution and allow the Mo product to be transferred to another location for purification. .

Figure 7 is a schematic of the bench-top cold feeds for solution-composition control and column operations, as well as the off-gas recovery system. During operation, the off gas is contained in a closed-loop/recycle system. At the end of operation, the off gas will be evacuated into a tank for decay storage, using the three-tank/two-pump system shown in Figure 6. The gas will need to be stored in the tank for about 3 months to allow the short-lived Xe and I radioisotopes to decay.

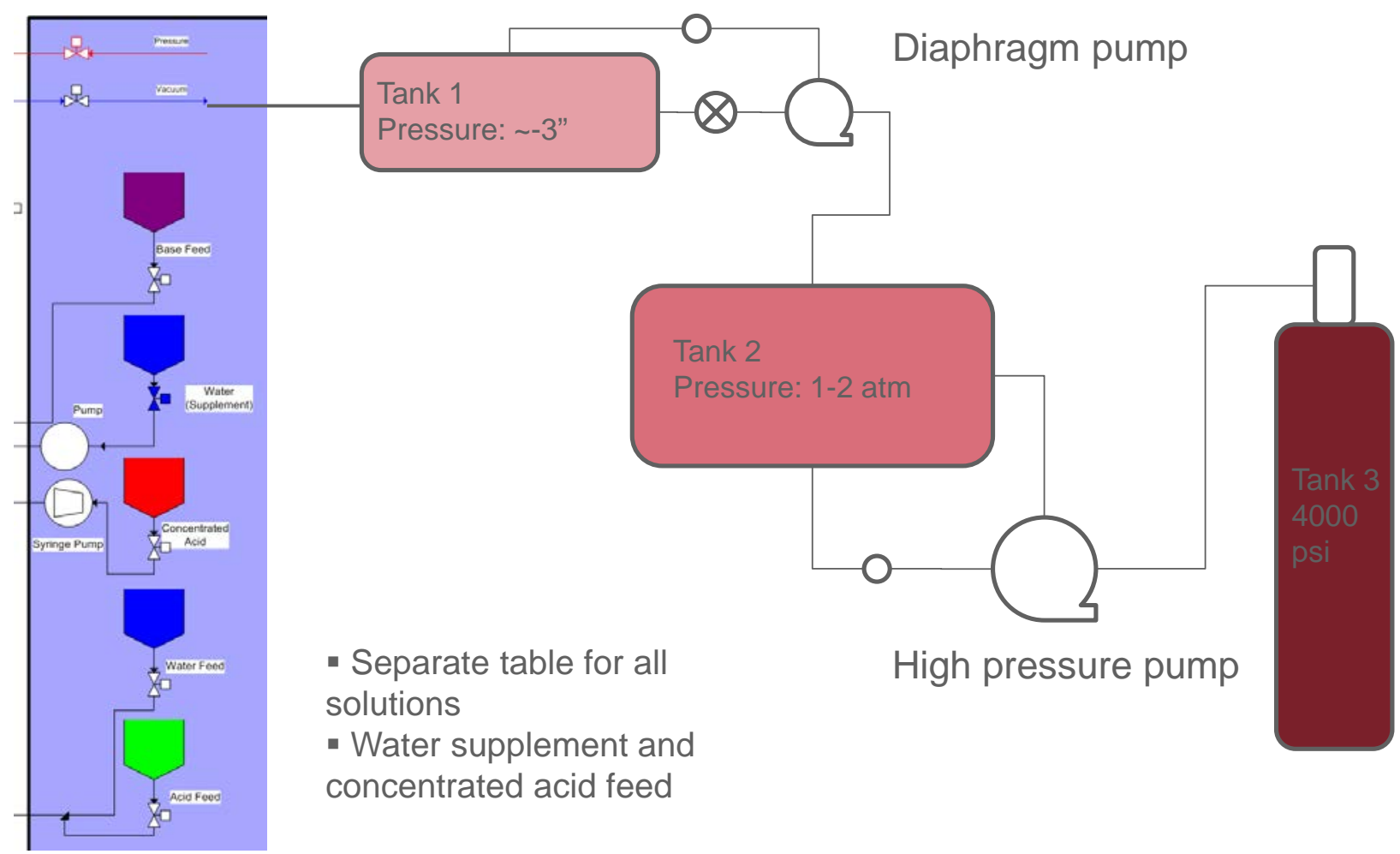

FIGURE 7 Cold-feed Table and Off-gas Collection System 


\section{SCHEDULE FOR THE MINI-SHINE/MIPS EXPERIMENTS}

The proposed (draft) schedules for the mini-SHINE and mini-MIPS experiments are shown in Tables 1 and 2.The schedules are phased approaches in three ways. Phase 1 is a prelude to the higher power densities required in Phase 2. Further, both phases are scheduled to go through a schedule of less-complex to more-complex experiments, and these experiments will be run through a series of increasing power and time irradiations to reach the final objectives. Initial experiments will be run using only water as the target solution; gamma radiolysis will produce hydrogen and oxygen only and will test the catalytic convertor, gas-recycle loop, off-gas collection system, the off-gas monitoring system, solution sampling loop, and internal target solution thermocouples and cooling loop.

Once these operations have been tested, the target solution will be changed to sodiumnitrate and then sodium-sulfate solutions. This will allow testing of the solution-monitoring systems, as well as the previously tested systems.

Once all checks out, a uranyl-nitrate solution will be used as the target solution. Short times and power runs will allow us to test the Mo-recovery column operations. Following successful experiments with the uranyl-nitrate system, uranyl-sulfate solutions will be used as the target solutions.

Phase 2 will begin once all systems have been tested under Phase 1 conditions. 
TABLE 1 Draft Schedule for Mini-SHINE Experiments

\begin{tabular}{|c|c|c|c|}
\hline $\mathrm{A} / \mathrm{M} / \mathrm{D}$ & Description & Start Date & $\begin{array}{c}\text { Finish } \\
\text { Date }\end{array}$ \\
\hline A & $\begin{array}{l}\text { Use Argonne mini-SHINE to provide operational data for } \\
\text { the SHINE target solutions for both nitrate and sulfate } \\
\text { media with uranium concentrations relevant to SHINE } \\
\text { target solution concentrations }\end{array}$ & $10 / 1 / 2011$ & 9/30/2012 \\
\hline M1 & Complete mini-SHINE Phase 1 water irradiations & & $12 / 31 / 2011$ \\
\hline M2 & Complete mini-SHINE Phase 1 sodium-sulfate irradiations & & $2 / 28 / 2012$ \\
\hline M3 & $\begin{array}{l}\text { Submit letter report documenting the design of the Phase } 2 \\
\text { mini-SHINE experimental setup }\end{array}$ & & 3/31/2012 \\
\hline M4 & $\begin{array}{l}\text { Complete procurements and fabrication of parts for } \\
\text { Phase } 2 \text { mini-SHINE }\end{array}$ & & $4 / 30 / 2012$ \\
\hline M5 & $\begin{array}{l}\text { Complete mini-SHINE Phase } 1 \text { uranium-sulfate } \\
\text { irradiations }\end{array}$ & & $6 / 15 / 2012$ \\
\hline M6 & Complete assembly and testing of the Phase 2 mini-SHINE & & $6 / 30 / 2012$ \\
\hline M7 & $\begin{array}{l}\text { Complete letter report on results of Phase } 1 \text { mini-SHINE } \\
\text { experiments }\end{array}$ & & $8 / 31 / 2012$ \\
\hline M8 & Complete FY-12 mini-SHINE experiments & & 9/30/2012 \\
\hline D1 & $\begin{array}{l}\text { Letter report documenting the design of the Phase } 2 \text { mini- } \\
\text { SHINE experimental setup }\end{array}$ & & 3/31/2012 \\
\hline D2 & $\begin{array}{l}\text { Letter report on results of Phase } 1 \text { mini-SHINE } \\
\text { experiments }\end{array}$ & & $8 / 31 / 2012$ \\
\hline
\end{tabular}




\section{TABLE 2 Draft Schedule for Mini-MIPS Experiments}

\begin{tabular}{|c|c|c|c|}
\hline $\mathrm{A} / \mathrm{M} / \mathrm{D}$ & Description & Start Date & $\begin{array}{l}\text { Finish } \\
\text { Date }\end{array}$ \\
\hline A & Mini-MIPS experiments & $10 / 1 / 2011$ & 9/30/2012 \\
\hline M1 & Complete mini-MIPS Phase 1 water irradiations & & $12 / 31 / 2011$ \\
\hline M2 & Complete mini-MIPS Phase 1 sodium-nitrate irradiations & & $1 / 31 / 2012$ \\
\hline M3 & $\begin{array}{l}\text { Write letter report documenting the design of the Phase } 2 \\
\text { mini-MIPS experimental setup }\end{array}$ & & 3/31/2012 \\
\hline M4 & $\begin{array}{l}\text { Complete procurements and fabrication of parts for } \\
\text { Phase } 2 \text { mini-MIPS }\end{array}$ & & 4/30/2012 \\
\hline M5 & Complete Phase 1 uranyl-nitrate irradiations & & $5 / 31 / 2012$ \\
\hline M5 & Complete assembly and testing of the Phase 2 mini-MIPS & & $6 / 30 / 2012$ \\
\hline M6 & $\begin{array}{l}\text { Complete letter report on results of Phase } 1 \text { mini-MIPS } \\
\text { experiments }\end{array}$ & & 7/31/2012 \\
\hline M7 & Complete FY-12 mini-MIPS experiments & & $9 / 30 / 2012$ \\
\hline D1 & $\begin{array}{l}\text { Letter report documenting the design of the Phase } 2 \text { mini- } \\
\text { MIPS experimental setup }\end{array}$ & & $3 / 31 / 2012$ \\
\hline D2 & $\begin{array}{l}\text { Letter report on results of Phase } 1 \text { mini-MIPS } \\
\text { experiments }\end{array}$ & & $7 / 31 / 2012$ \\
\hline
\end{tabular}


This page intentionally left blank 


\section{Argonne}

Chemical Science and Engineering Division

Argonne National Laboratory

9700 South Cass Avenue, Bldg. 205

Argonne, IL 60439-4837

www.anl.gov 